\title{
Tailoring iridium luminescence and gold nanoparticle size for imaging of microvascular blood flow
}

\author{
Nicola J Rogers ${ }^{1}$, Hannah C Jeffery ${ }^{2}$, Sunil Claire ${ }^{3}$, David J Lewis ${ }^{1, \ddagger}$, Gerald Zikeli ${ }^{1}$, Nikolas J \\ Hodges $^{3,4}$, Stuart Egginton ${ }^{2,5}$, Gerard B Nash ${ }^{2,3}$ \& Zoe Pikramenou*,1,3 \\ ${ }^{1}$ School of Chemistry, University of Birmingham, Edgbaston, B15 2TT, UK \\ ${ }^{2}$ Institute of Cardiovascular Sciences, University of Birmingham, Edgbaston, B15 2TT, UK \\ ${ }^{3}$ Physical Sciences of Imaging in the Biological Sciences Doctoral Training Centre, University of Birmingham, Edgbaston, B15 2T, \\ UK \\ ${ }^{4}$ School of Biosciences, University of Birmingham, Edgbaston, B15 2TT, UK \\ ${ }^{5}$ School of Biomedical Sciences, Faculty of Biological Sciences, University of Leeds, Leeds, LS2 9JT, UK \\ * Author for correspondence: z.pikramenou@bham.ac.uk \\ $\ddagger$ Current address: School of Materials, University of Manchester, Manchester, M13 9PL, UK
}

\begin{abstract}
Aim: Imaging of blood flow in narrow channels and close to vessel walls is important in cardiovascular research for understanding pathogenesis. Our aim was to provide novel nanoprobes with visible emission and long lifetimes as trackers of flow. Materials \& methods: Gold nanoparticles coated with an iridium complex were prepared. Luminescence imaging was used to monitor their flows in different hematocrit blood and in murine tissues. Results: The velocities are independent of hematocrit level and the nanoparticles entering blood circulation can be clearly detected in vessels in lungs, mesentery and the skeletal muscle. Conclusion: The work introduces for the first time iridium-based yellow-green luminescence with nanoparticle size of $100 \mathrm{~nm}$ for visualizing and monitoring flows with much higher resolution than conventional alternatives.
\end{abstract}

First draft submitted: 15 June 2017; Accepted for publication: 29 August 2017; Published online: 29 September 2017

Keywords: blood flow $\bullet$ gold nanoparticles $\bullet$ imaging $\bullet$ luminescence $\bullet$ metal probes

In cardiovascular research, visualization of the vascular tree and characterization of the blood flow across vessels is valuable for an understanding of the disease pathogenesis and the controlled delivery of therapeutic agents. Recent advances in fluorescence microscopy have revealed the potential of fluorescence imaging [1] to monitor changes in cardiac structure upon therapeutic treatment [2]. However, methods for tracking blood flow based on fluorescently labeled blood cells or microparticles in vitro and in vivo [3-5] limit the spatial resolution to a few micrometers, which is problematic for narrow vessels and tracking flow rates near to the channel walls. The flow fields generated within the sophisticated network of micrometer-sized blood vessels, produce unsteady flow phenomena that can also influence pathophysiological responses within the vascular bed, such as inflammation and thrombosis. Luminescent nanoparticles have been recognized as potential optical imaging probes, which can interrogate the complex spatial and temporal information in flow dynamics [6-10]. Most importantly, they can provide rheological detail currently unavailable in clinical practice, which employs organic fluorescent dyes (e.g., fluorescein angiography). Quantum dots have been studied as potential imaging agents of the vasculature when they are coated with silica or polymer shells for biocompatibility or increase of their size [8,11-13].It is important for the luminescent probes to be inert in the challenging environment of blood and display clear luminescence signal due to the the high concentration of the red blood cells (RBC) which absorb light and the many constituents in the plasma which can interact with the probes. Gold nanoparticles are attractive in biomedical research due to their easily tunable size, water solubility and low toxicity [14-18]. Their applications in fluorescence imaging are limited by the gold resonance which quenches organic probe fluorescence [14]. 


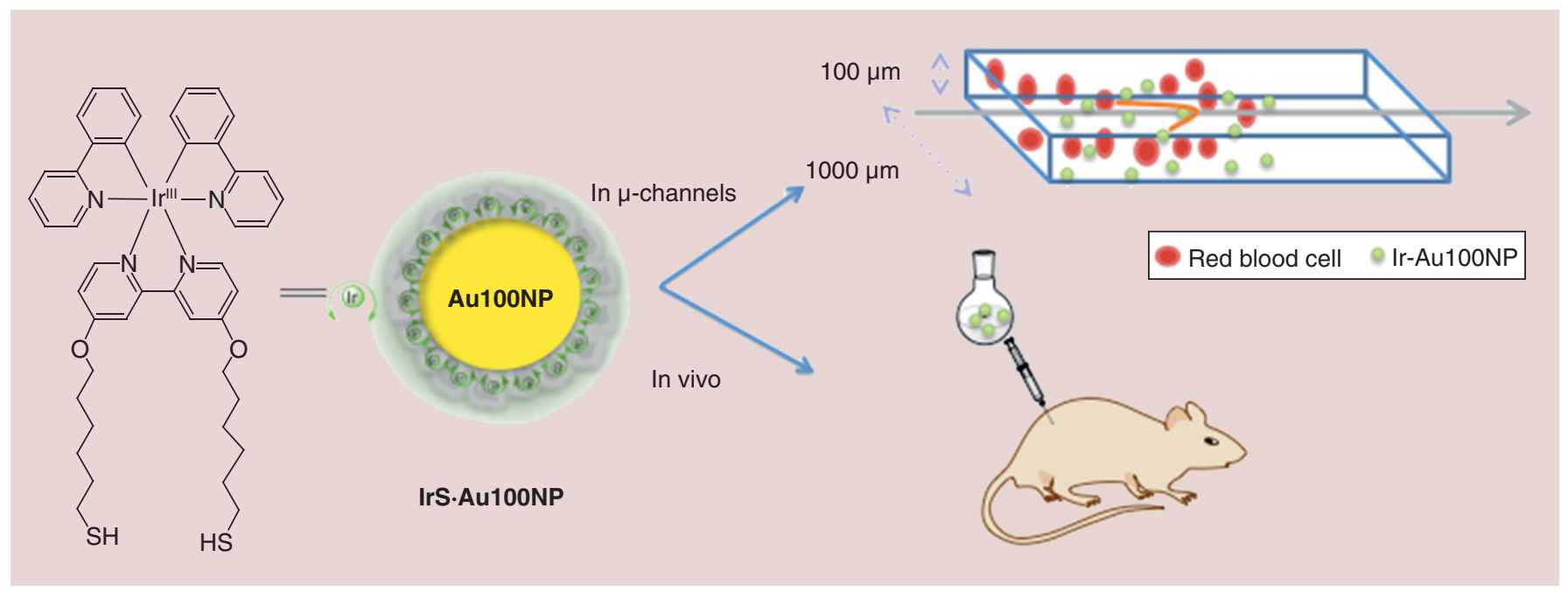

Figure 1. Luminescent iridium-coated gold nanoparticles in imaging of blood flows and in murine tissues.

In this paper, we introduce iridium-coated luminescent gold nanoparticles for imaging of blood flow dynamics. We have developed, water-soluble iridium-coated nanoparticles using a surfactant-mediated coating strategy $[19,20]$ which allows formation of stable up to $100 \mathrm{~nm}$ luminescent gold nanoparticles in water. Gold provides an inert scaffold with sizes that can be tuned for the requirement of imaging, yet retaining the water solubility. Gold's high affinity for thiols provides a versatile and efficient attachment method. By attaching the iridium metal complex onto gold, we convey its distinct photophysical properties $[5,21,22]$ to the nanoscale, leading to photostable nanoparticles with long-lived, visible luminescence and a large Stokes shift, which is desirable for biomedical applications [23-25]. Although, iridium-coated gold nanoparticles [26-28] have been previously reported by other methods, their size was limited to $5 \mathrm{~nm}$ and the nanoparticles were nonluminescent, even though iridium metal complexes are popular molecular imaging probes in biological cells [29]. We have synthesized an iridium complex for attachment to gold nanoparticles which offers an optical window for excitation $(350-400 \mathrm{~nm})$ and luminescence $(500-700 \mathrm{~nm})$ where absorption of blood is relatively low (Figure 1) [30]. The gold nanoparticle allows attachment of multiple photoactive metals and visualization of the probes in low concentrations, yet detectable by luminescence. We have used a fluorinated surfactant for the preparation of the gold nanoparticles [19] 13 and $100 \mathrm{~nm}$, IrS•AuNP13 and IrS•AuNP100 respectively, which have been isolated and fully characterized. The $100 \mathrm{~nm}$ gold particles have been identified as an ideal size for visualization in blood as they provide a surface with high coating of luminescent probes and are visualized as nonaggregated particles in flow, even though they are in subdiffraction limit. The $13 \mathrm{~nm}$ nanoparticles could not be visualized under the same conditions. The photophysical studies of the nanoparticles reveal enhanced luminescence lifetimes and quantum yields as compared with the molecular iridium complex. Using in vitro assays, we demonstrate that the $100 \mathrm{~nm}$ nanoparticles can be used as luminescent flow tracers in blood and show that their velocity is not altered relative to that of (RBC), irrespective of the percentage hematocrit reaching physiologically relevant values of RBC concentrations. Importantly, we also report their detection within surgically excised organs from a murine animal model injected with the luminescent nanoparticles, which further supports their potential as imaging agents.

\section{Materials \& methods}

General

All solvents were purchased from Fisher or Sigma-Aldrich (Dorset, UK), all anhydrous solvents were dried over $3 \AA$ molecular sieves under $\mathrm{N}_{2}$ (g) for $1 \mathrm{~h}$ or by PureSolv-EN solvent purification system. Reagent grade 4,4'dimethoxy-2,2'-bipyridine, 6-bromohex-1-ene, $\mathrm{HAuCl}_{4}, \mathrm{IrCl}_{3}, \mathrm{Zonyl}_{7950}{ }^{\circledR} \mathrm{CH}_{3} \mathrm{C}\left(=\mathrm{CH}_{2}\right) \mathrm{COOC}_{2} \mathrm{H}_{4}\left(\mathrm{CF}_{2}\right)_{\mathrm{n}} \mathrm{F}$ and 2-phenylpyridine were purchased from Sigma-Aldrich. 4,4'-dihydroxy-2,2'-bipyridine [31] BpyHex [19], $\left[\operatorname{Ir}(\mathrm{ppy})_{2}(\mu-\mathrm{Cl})\right]_{2}$ [32] and AuNP13 [33] were synthesized according to published procedures. Detailed synthetic scheme of the metal complex is included in the Supplementary Information. 
$\left[\operatorname{Ir}(p p y)_{2}(B p y H e x)\right] C l$ The cyclometalled iridium(III) dimer $\left[\operatorname{Ir}(\mathrm{ppy})_{2}(\mu-\mathrm{Cl})\right]_{2}(634 \mathrm{mg}, 0.591 \mathrm{mmol})$ and BpyHex (310 mg, $0.876 \mathrm{mmol}, 1.5 \mathrm{eq}$ ) were dissolved in $\mathrm{CH}_{2} \mathrm{Cl}_{2} / \mathrm{CH}_{3} \mathrm{OH}$ (45 ml, 2:1) and refluxed overnight at $60^{\circ} \mathrm{C}$ under nitrogen. Following cooling, the solvent was removed in vacuo to render a yellow residue. The residue was purified by chromatography on silica $\left(\mathrm{CH}_{2} \mathrm{Cl}_{2}: \mathrm{CH}_{3} \mathrm{OH} 10: 1\right) R_{\mathrm{f}}=0.4,4$ to give $\left[\mathrm{Ir}(\mathrm{ppy})_{2}(\mathrm{BpyHex})\right] \mathrm{Cl}$ as a yellow powder $\left(0.602 \mathrm{~g}, 0.677 \mathrm{mmol}, 77 \%\right.$ yield). $R_{\mathrm{f}}=0.44\left(\mathrm{CH}_{2} \mathrm{Cl}_{2}: \mathrm{CH}_{3} \mathrm{OH} 10: 1\right) .{ }^{1} \mathrm{H} \mathrm{NMR}(400 \mathrm{MHz}$, $d_{6}$-DMSO): $\delta_{\mathrm{H}}=8.46\left(\mathrm{~s}, 2 \mathrm{H}, \mathrm{H}_{3}\right), 8.25\left(\mathrm{~d}, 2 \mathrm{H},{ }^{3} J_{\mathrm{Hd}}=8.2 \mathrm{~Hz}, \mathrm{H}_{\mathrm{e}}\right), 7.98-7.88\left(\mathrm{~m}, 4 \mathrm{H}, \mathrm{H}_{\mathrm{d}} / \mathrm{H}_{\mathrm{h}}\right), 7.69(\mathrm{~d}, 2 \mathrm{H}$, $\left.{ }^{3} J_{\mathrm{Hc}}=5.6 \mathrm{~Hz}, \mathrm{H}_{\mathrm{b}}\right), 7.59\left(\mathrm{~d}, 2 \mathrm{H},{ }^{3} J_{\mathrm{H} 5}=6.6 \mathrm{~Hz}, \mathrm{H}_{6}\right), 7.28\left(\mathrm{dd}, 2 \mathrm{H},{ }^{3} J_{\mathrm{H} 6}=6.6 \mathrm{~Hz},{ }^{4} J_{\mathrm{H} 3}=2.5 \mathrm{~Hz}, \mathrm{H}_{5}\right), 7.19$ $\left(\mathrm{t}, 2 \mathrm{H},{ }^{3} J_{\mathrm{Hd}} \approx{ }^{3} J_{\mathrm{Hb}}=5.7 \mathrm{~Hz}, \mathrm{H}_{\mathrm{c}}\right), 7.00\left(\mathrm{t}, 2 \mathrm{H},{ }^{3} J_{\mathrm{Hh}} \approx{ }^{3} J_{\mathrm{Hj}}=7.5 \mathrm{~Hz}, \mathrm{H}_{\mathrm{i}}\right), 6.88\left(\mathrm{t}, 2 \mathrm{H},{ }^{3} J_{\mathrm{Hk}} \approx{ }^{3} J_{\mathrm{Hi}}=7.5 \mathrm{~Hz}\right.$, $\left.\mathrm{H}_{\mathrm{j}}\right), 6.19\left(\mathrm{~d}, 2 \mathrm{H},{ }^{3} J_{\mathrm{Hj}}=7.5 \mathrm{~Hz}, \mathrm{H}_{\mathrm{k}}\right), 5.90-5.76\left(\mathrm{~m}, 2 \mathrm{H}, \mathrm{H}_{11}\right), 5.09-4.95\left(\mathrm{~m}, 4 \mathrm{H}, \mathrm{H}_{12} / \mathrm{H}_{13}\right), 4.24(\mathrm{t}, 4 \mathrm{H}$, $\left.{ }^{3} J_{\mathrm{H} 8}=6.3 \mathrm{~Hz}, \mathrm{H}_{7}\right), 2.16-2.06\left(\mathrm{~m}, 4 \mathrm{H}, \mathrm{H}_{10}\right), 1.85-1.73\left(\mathrm{~m}, 4 \mathrm{H}, \mathrm{H}_{8}\right), 1.59-1.46\left(\mathrm{~m}, 4 \mathrm{H}, \mathrm{H}_{9}\right) .{ }^{13} \mathrm{C} \mathrm{NMR}$ (100 MHz, d6 -DMSO): $\delta_{\mathrm{C}}=150.5\left(\mathrm{C}_{6}\right), 148.7\left(\mathrm{C}_{\mathrm{b}}\right), 138.5 / 138.3\left(\mathrm{C}_{\mathrm{d}} / \mathrm{C}_{11}\right), 131.1\left(\mathrm{C}_{\mathrm{k}}\right), 130.1\left(\mathrm{C}_{\mathrm{j}}\right), 125.9$ $\left(\mathrm{C}_{\mathrm{h}}\right), 125.0\left(\mathrm{C}_{\mathrm{c}}\right), 123.8\left(\mathrm{C}_{\mathrm{i}}\right), 121.9\left(\mathrm{C}_{\mathrm{e}}\right), 115.1\left(\mathrm{C}_{12}\right), 114.5\left(\mathrm{C}_{5}\right), 111.9\left(\mathrm{C}_{3}\right), 69.1\left(\mathrm{C}_{7}\right), 32.6\left(\mathrm{C}_{10}\right), 27.6\left(\mathrm{C}_{8}\right)$, 24.5 (C9). TOF ES-MS(+): m/z 853.5 [M] ${ }^{+}$IR $\nu_{\max }\left(\mathrm{cm}^{-1}\right): 3045,2940,1606,1472,1436,1341,1284,1226$, $1031,994,756$.

$\operatorname{IrSAc}$ thioacetic acid $(564 \mu \mathrm{l}, 7.890 \mathrm{mmol}$ ) and 1,1'-azobiscyclohexane carbonitrile (ABCN, $756 \mathrm{mg}$, $3.093 \mathrm{mmol}$ ) in anhydrous tetrahydrofuran (THF; $10 \mathrm{ml}$ ) were heated at $60^{\circ} \mathrm{C}$ under $\mathrm{N}_{2}(\mathrm{~g})$ for $30 \mathrm{~min}$. $\left[\operatorname{Ir}(\text { ppy })_{2}(\right.$ BpyHex $\left.)\right] \mathrm{Cl}(600 \mathrm{mg}, 0.675 \mathrm{mmol})$ in anhydrous THF $(40 \mathrm{ml})$ was added dropwise to the mixture, which was then stirred at $60^{\circ} \mathrm{C}$ under $\mathrm{N}_{2}(\mathrm{~g})$. The progress of the reaction was monitored by the disappearance of the terminal olefins by ${ }^{1} \mathrm{H}$ NMR. Thioacetic acid $(100 \mu \mathrm{l}, 1.399 \mathrm{mmol})$ and ABCN $(125 \mathrm{mg}, 0.512 \mathrm{mmol})$ were added after $18 \mathrm{~h}$, another portion of thioacetic acid $(120 \mathrm{ml}, 1.679 \mathrm{mmol})$ and ABCN $(150 \mathrm{mg}, 0.614 \mathrm{mmol})$ was added after $22 \mathrm{~h}$. After a total of $45 \mathrm{~h}$, the reaction was pushed to completion and the ABCN was quenched with saturated $\mathrm{NaHCO}_{3}$ (aq) $\left(150 \mathrm{ml}\right.$ ). The solution was extracted with $\mathrm{CH}_{2} \mathrm{Cl}_{2} / \mathrm{H}_{2} \mathrm{O}$ and dried over $\mathrm{MgSO}$, and filtered. The solvent was removed in vacuo to render a dark brown viscous residue which was purified by column chromatography on silica $\left(\mathrm{CH}_{2} \mathrm{Cl}_{2}: \mathrm{CH}_{3} \mathrm{OH} 10: 1\right) R_{\mathrm{f}}=0.56$, to give IrBpySAc as a bright yellow solid (459 mg, $0.441 \mathrm{mmol}, 65 \%$ yield). ${ }^{1} \mathrm{H}$ NMR $\left(400 \mathrm{MHz}, d_{6}-\mathrm{DMSO}\right): \delta_{\mathrm{H}}=8.44\left(\mathrm{~d}, 2 \mathrm{H},{ }^{4} J_{\mathrm{H} 5}=2.5 \mathrm{~Hz}, \mathrm{H}_{3}\right), 8.25(\mathrm{~d}, 2 \mathrm{H}$, $\left.{ }^{3} J_{\mathrm{Hd}}=8.1 \mathrm{~Hz}, \mathrm{H}_{\mathrm{e}}\right), 7.96-7.86\left(\mathrm{~m}, 4 \mathrm{H}, \mathrm{H}_{\mathrm{d}} / \mathrm{H}_{\mathrm{h}}\right), 7.68\left(\mathrm{~d}, 2 \mathrm{H},{ }^{3} J_{\mathrm{Hc}}=5.1 \mathrm{~Hz}, \mathrm{H}_{\mathrm{b}}\right), 7.58\left(\mathrm{~d}, 2 \mathrm{H},{ }^{3} J_{\mathrm{H} 5}=6.4 \mathrm{~Hz}\right.$, $\left.\mathrm{H}_{6}\right), 7.27\left(\mathrm{dd}, 2 \mathrm{H},{ }^{3} J_{\mathrm{H} 6}=6.4 \mathrm{~Hz},{ }^{4} J_{\mathrm{H} 3}=2.4 \mathrm{~Hz}, \mathrm{H}_{5}\right), 7.18\left(\mathrm{t}, 2 \mathrm{H},{ }^{3} J_{\mathrm{Hd}} \approx{ }^{3} J_{\mathrm{Hb}}=5.7 \mathrm{~Hz}, \mathrm{H}_{\mathrm{c}}\right), 6.99((\mathrm{t}, 2 \mathrm{H}$, $\left.{ }^{3} J_{\mathrm{Hj}} \approx{ }^{3} J_{\mathrm{Hh}}=7.5 \mathrm{~Hz}, \mathrm{H}_{\mathrm{i}}\right), 6.88\left(\mathrm{t}, 2 \mathrm{H},{ }^{3} J_{\mathrm{Hk}} \approx{ }^{3} J_{\mathrm{Hi}}=7.4 \mathrm{~Hz}, \mathrm{H}_{\mathrm{j}}\right), 6.18\left(\mathrm{~d}, 2 \mathrm{H},{ }^{3} J_{\mathrm{Hj}}=6.6 \mathrm{~Hz}, \mathrm{H}_{\mathrm{k}}\right), 4.21(\mathrm{t}, 4 \mathrm{H}$, $\left.{ }^{3} J_{\mathrm{H} 8}=6.1 \mathrm{~Hz}, \mathrm{H}_{7}\right), 2.83\left(\mathrm{t}, 4 \mathrm{H},{ }^{3} J_{\mathrm{H} 11}=7.2 \mathrm{~Hz}, \mathrm{H}_{12}\right), 2.30\left(\mathrm{~s}, 6 \mathrm{H}, \mathrm{H}_{15}\right), 1.80-1.71\left(\mathrm{~m}, 4 \mathrm{H}, \mathrm{H}_{10}\right), 1.56-1.48$ $\left(\mathrm{m}, 4 \mathrm{H}, \mathrm{H}_{8}\right), 1.46-1.34\left(\mathrm{~m}, 8 \mathrm{H}, \mathrm{H}_{9} / \mathrm{H}_{11}\right) .{ }^{13} \mathrm{C}$ NMR (100 MHz, d $d^{6}$-DMSO): $\delta_{\mathrm{C}}=177.2 / 169.9 / 156.9 / 143.9$ (quaternary C), $150.5\left(\mathrm{C}_{6}\right), 148.7\left(\mathrm{C}_{\mathrm{b}}\right), 138.5 / 125.0\left(\mathrm{C}_{\mathrm{d}} / \mathrm{C}_{\mathrm{h}}\right), 131.1\left(\mathrm{C}_{\mathrm{k}}\right), 130.1\left(\mathrm{C}_{\mathrm{j}}\right), 123.8\left(\mathrm{C}_{\mathrm{c}}\right), 121.9\left(\mathrm{C}_{\mathrm{i}}\right)$, $119.9\left(\mathrm{C}_{\mathrm{e}}\right), 114.5\left(\mathrm{C}_{5}\right), 111.9\left(\mathrm{C}_{3}\right), 69.2\left(\mathrm{C}_{7}\right), 30.6\left(\mathrm{C}_{15}\right), 29.0\left(\mathrm{C}_{8}\right), 28.2\left(\mathrm{C}_{12}\right), 27.7\left(\mathrm{C}_{10}\right), 26.5 / 24.8\left(\mathrm{C}_{9} / \mathrm{C}_{11}\right)$. TOF MALDI-MS(+): m/z $1064.20[\mathrm{M}+\mathrm{Na}]^{+}$, $1006.19[\mathrm{M}-\mathrm{Cl}]^{+}$. HRMS $\left(\mathrm{ES}^{+}\right)$: Calc. for $\mathrm{C}_{48} \mathrm{H}_{52} \mathrm{IrN}_{4} \mathrm{O}_{4} \mathrm{~S}_{2}$ 1005.3060, found 1005.3046 Anal. calcd for $\mathrm{C}_{48} \mathrm{H}_{52} \mathrm{ClIrN}_{4} \mathrm{O}_{4} \mathrm{~S}_{2}$ : C 55.4, H 5.0, N 5.4. Found: C 55.1, H 4.9, N 5.2. IR $\nu_{\max }\left(\mathrm{cm}^{-1}\right): 2925,1682,1605,1476,1417,1337,1269,1225,1063,1030,952,757$. UV-VIS $\left(\mathrm{CH}_{3} \mathrm{CN}\right) \lambda_{\max }[\mathrm{nm},(\log \varepsilon)]=228$ (5.7), 256 (5.7), 295 (5.3), 346 (4.9), 420 (4.5).

IrSH To IrSAc $(50 \mu \mathrm{l}, 7.96 \mathrm{mM}$ in $\mathrm{MeCN}, 398 \mathrm{nmol})$ was added $\mathrm{NH}_{4} \mathrm{OH}_{(\mathrm{aq})}$ solution $(50 \mu \mathrm{l}, 30 \% \mathrm{w} / w)$. The mixture was stirred for $10 \mathrm{~min}$ in a sealed vial to render IrSH directly prior to titration into the colloid. TOF MALDI-MS(+): $920.15[\mathrm{M}-\mathrm{Cl}]^{+}$.

$\operatorname{IrS} \bullet A$ NP13 Zonyl7950 ${ }^{\circledR}$ (MW ca. 500, $1 \mu \mathrm{l}, 1.15 \mathrm{~g} \mathrm{ml}^{-1}$ ) was added in a solution of $13 \mathrm{~nm}$ citrate gold nanoparticles $(1 \mathrm{ml}, 9 \mathrm{~nm}$ nanoparticles, $\zeta$ potential at $2 \mathrm{~nm}$ in deionized water $=-40 \pm 5 \mathrm{mV}$, diameter $=13 \pm 4 \mathrm{~nm}$ [dynamic light scattering (DLS) number distribution], = $29 \pm 12 \mathrm{~nm}$ [86\%], $998 \pm 624 \mathrm{~nm}$ [14\%; DLS intensity distribution]) to give fluorosurfactant coated nanoparticles ( $9 \mathrm{~nm}$ nanoparticles), with a final fluorosurfactant concentration of approximately $1 \mathrm{ml}$. Isolated Z•AuNP13, by three rounds of centrifugation, decantation of the supernatant and resuspension of the pellet have a $\zeta$ potential of $-61 \pm 4 \mathrm{mV}$ ( $2 \mathrm{~nm}$ in deionized water) and diameter of $20 \pm 2 \mathrm{~nm}$ (DLS number distribution), and of $32 \pm 15 \mathrm{~nm}$ (DLS intensity distribution). A solution of $\mathrm{IrSH}\left(20 \mu \mathrm{l}, 3.5 \mathrm{mM}\right.$ [made in situ, $\mathrm{NH}_{4} \mathrm{OH}(\mathrm{aq}) 30 \% \mathrm{w} / \mathrm{w}: \mathrm{CH}_{3} \mathrm{CN}$ (1:1) solution]) was added to the fluorosurfactant/nanoparticle mixture (not isolated), and was stirred for $20 \mathrm{~min}$. The particles were centrifuged at $12,000 \times g$ for $15 \mathrm{~min}$ and the supernatant was decanted from each pellet to remove unbound material. The nanoparticles were resuspended in deionized water, and this was repeated twice to give IrS•AuNP13 UV-Vis $(\mathrm{H} 2 \mathrm{O}) \lambda_{\max }[\mathrm{nm}]=522$ surface plasmon resonance $(\mathrm{SPR})$. Diameter $=19 \pm 5 \mathrm{~nm}$ (DLS number distribution), $=340 \pm 166 \mathrm{~nm}(60 \%), 33 \pm 1 \mathrm{~nm}(38 \%), 4567 \pm 844 \mathrm{~nm}(2 \%)$ (DLS intensity distribution), $\zeta$ potential = 
$-35 \pm 3 \mathrm{mV}$ (isolated, $2 \mathrm{~nm}$ in deionized water diluent). Inductively coupled plasma optical emission spectroscopy (ICP-OES) Au:Ir atomic ratio = 106:1.

IrS•AuNP100 Zonyl7950 ${ }^{\circledR}$ (MW ca. 500, $1 \mu \mathrm{l}, 1.15 \mathrm{~g} \mathrm{ml}^{-1}$ ) was added to $1 \mathrm{ml}$ of AuNP100 ( $\zeta$ potential at $4 \mathrm{pM}$ in deionized water diluents $=-33 \pm 3 \mathrm{mV}$ ) to give fluorosurfactant coated nanoparticles with a $\zeta$ potential ( $4 \mathrm{pM}$ in deionized water diluent $)=-47 \pm 3 \mathrm{mV}$. IrSH $(15 \mu \mathrm{l}, 3.4 \mathrm{mM})$ solution was added to the nanoparticles and the solution was shaken and allowed to equilibrate at room temperature for $20 \mathrm{~min}$. The coated particles were centrifuged at 13,000 rpm for $90 \mathrm{~s}$ and resuspended in deionized water three-times to remove any unbound material, to give IrS•AuNP100. UV-Vis $\left(\mathrm{H}_{2} \mathrm{O}\right) \lambda_{\max }[\mathrm{nm}]=568$ (SPR). $\zeta$ Potential ( $4 \mathrm{pM}$ in deionized water diluent) $=-33 \pm 3 \mathrm{mV}$.

\section{Nanoparticle characterization}

The $\zeta$ potential and DLS measurements were performed using a Beckman-Coulter (High Wycombe, UK) DELSA NanoC system. The $\zeta$ potentials are quoted as the average of six runs and the machine was calibrated with a Malvern Instruments zeta potential transfer standard. DLS measurements are calculated by CONTIN analysis of the scattered light intensity autocorrelation function. Nanoparticle Tracking Analysis was performed using a Nanosight LM-10 (Nanosight, Salisbury, UK) system equipped with a $488 \mathrm{~nm}$ laser in scattering mode, using the analysis of at least 2000 tracks. Transmission electron microscopy (TEM) was performed using a JEOL JEM$1200 \mathrm{EX}$ electron microscope fitted with a Gatan camera by drying colloid onto Formvar ${ }^{\circledR}$-coated copper grids (Agar Scientific, Stansted, UK). ICP-OES was performed on colloidal suspensions which were digested in ultrapure aqua regia and then diluted ten-fold in deionized water, to gain gold and iridium concentrations at the University of Warwick, using a Perkin-Elmer 5300DV ICP-OES system. PlasmaCal Calibration standards of 1000 ppm gold and iridium (QMX Laboratories, Dunmow, UK) were diluted to determine linear calibration curves with $\mathrm{R}^{2}>0.999$ in all cases. For confocal microscopy imaging of the nanoparticles, the aqueous colloid was mixed with hydromount nonfluorescing aqueous mounting media (national diagnostics), and mounted between a glass coverslip and a glass microscope slide, and dried in the fridge for $24 \mathrm{~h}$ before imaging to set the particles into a rigid matrix.

\section{Spectroscopic studies}

Photophysical measurements and luminescence microscopy UV-Vis absorption spectroscopy measurements were performed on a Varian Cary 5000 spectrometer and steady-state luminescence measurements were executed on an Edinburgh Instruments FLS920 spectrometer. Quantum yield measurements were made on the spectrometer using an integrating sphere. Emission lifetimes were measured with a $375 \mathrm{~nm}$ diode laser excitation source and the time-correlated single-photon counting module of the FLS920, and were tail-fitted with the Edinburgh Instruments F900 software. Epiluminescence images were acquired with the FLSP920 appended to an Olympus IX71 Inverted Microscope and confocal laser scanning microscopy was performed using a Leica TCS SP2 confocal microscope (Leica Microsystems, Milton Keynes, UK).

\section{MTT assay}

Cells were seeded in a 96-well plate at density of 8000 cells per well. Following incubation for $24 \mathrm{~h}$ at $37^{\circ} \mathrm{C}$ in $5 \% \mathrm{CO}_{2}$, removal of media and a phosphate-buffered saline (PBS) wash, particles or water in complete media at the required concentrations were added for a further 24-h incubation. After 24-h treatment the cell media was removed and cells washed twice with PBS, followed by incubation in complete cell media containing MTT (3-(4,5-Dimethylthiazol-2-yl)-2,5-Diphenyltetrazolium Bromide) at a concentration of $0.5 \mathrm{mg} \mathrm{ml}-1$ (100 $\mu \mathrm{l} \mathrm{per}$ well). After 3-h incubation, the supernatant was discarded and DMSO (200 $\mu \mathrm{l}$ per well) added to dissolve the resultant formazan crystals. Absorbance against a DMSO blank was immediately read in a microplate reader at $590 \mathrm{~nm}$. Percentage cell viability was expressed relative to the untreated cells in complete media.

\section{Isolation of RBC \& preparation of defined percentage hematocrit suspensions}

Venous blood from healthy individuals was added to citrate phosphate dextrose adenine solution (Sigma-Aldrich) in sterile $15 \mathrm{ml}$ round bottom polystyrene tubes (Sterilin, Appleton Woods, Birmingham, UK) at ratio of 9:1 following informed consent and with approval from the University of Birmingham Local Ethical Review Committee. RBCs were isolated by centrifugation ( $2500 \mathrm{rpm}, 10 \mathrm{~min}$ ) and washed twice with $10 \mathrm{ml}$ PBS (3000 rpm, $10 \mathrm{~min})$. RBC pellets from $27 \mathrm{ml}$ venous blood were pooled and centrifuged $(3000 \mathrm{rpm}, 5 \mathrm{~min})$ to pack cells. The supernatant was removed and the packed RBC diluted 1:1 with PBS. RBC concentration was determined using a Coulter 
Particle Count and Size Analyzer (Beckman Coulter). Hematocrit (\% packed cell volume) of the RBC suspension was also measured using the microhematocrit method in which RBC suspension was drawn into glass capillary tubes under capillary action and one end of the tube sealed by melting the glass. The capillary tube was centrifuged $(15,000 \times g, 5 \mathrm{~min})$ to separate the RBC from the liquid phase and hematocrit was calculated by dividing the length of the RBC column into the total length of the RBC suspension column. No corrections were made for small volumes of solution trapped within the tightly packed RBC. A total of $2.5 \mathrm{ml}$ suspensions of known hematocrit were prepared by dilution with PBS. In order to allow tracking of RBC, the preparations were spiked with $2.8 \times 10^{7}$ CellTracker Green ${ }^{\mathrm{TM}} / 5$-Chloromethylfluorescein Diacetate (CMFDA; Molecular Probes, Life Technologies, Paisley, UK)-labeled RBC per $2.5 \mathrm{ml}$ RBC suspension. The number of labeled RBC added was negligible compared with the total present (0.27-0.79\%) and was kept constant, irrespective of the hematocrit, in order that the frequency of labeled cells passing the field of view under flow conditions was uniform across test conditions. To investigate effects of RBC aggregation on the dynamics of nanoparticles under flow conditions, $62.5 \%$ of the fluid phase was replaced with solutions of different molecular weight dextrans: $1.6 \%$ high molecular weight $500 \mathrm{kDa}$ dextran (Dextran500) to induce aggregation and 3.25\% low-molecular-weight 40-kDa dextran (Dextran40) as a viscosity control.

Fluorescent labeling of RBC

The $90 \times 10^{6}$ washed RBCs were suspended in $15 \mathrm{ml}$ CMFDA $(10 \mu \mathrm{m})$ diluted in nonsupplemented medium M199 (Gibco, Invitrogen, Paisley, Scotland) and incubated $\left(37^{\circ} \mathrm{C}, 5 \% \mathrm{CO}_{2}\right)$ for $40 \mathrm{~min}$. Cells were pelleted by centrifugation (1500 rpm, $5 \mathrm{~min}$ ) then resuspended in $15 \mathrm{ml}$ medium M199 supplemented with $10 \%$ fetal calf serum and incubated $\left(37^{\circ} \mathrm{C}, 5 \% \mathrm{CO}_{2}\right)$ for $40 \mathrm{~min}$. Cells were pelleted by centrifugation ( $\left.1500 \mathrm{rpm}, 5 \mathrm{~min}\right)$, washed in $15 \mathrm{ml}$ PBS (1500 rpm, $5 \mathrm{~min}$ ) and resuspended in $800 \mu \mathrm{l}$ PBS. A total of $250 \mu \mathrm{l}$ volumes were added per $2.5 \mathrm{ml}$ preparation of each percentage of RBC suspension (hematocrit) as a component of the total diluent volume.

\section{Flow imaging}

Assays were performed using a flow system as described previously [34]. Briefly, prefabricated channel slides of rectangular cross-section ( $\mu$-slide $\mathrm{VI}^{0.1}$ noncoated, Ibidi $\mathrm{GmbH}$, Martinsried, Germany), channel dimensions $17 \mathrm{~mm}$ length (y-axis) x $1 \mathrm{~mm}$ width (x-axis) x $0.1 \mathrm{~mm}$ depth (z-axis), were pretreated with $4 \%$ bovine serum albumin solution in PBS for $3 \mathrm{~h}$, rinsed with PBS and mounted on the stage of an inverted microscope (Olympus IX-71) fitted with an LUCPLFLN 40X objective lens, numerical aperture 0.6, field number 22 and a variable focus collar with a working distance $2.7-4 \mathrm{~mm}$. A solution of $2 \mathrm{pM}$ nanoparticles in PBS buffer with $0-30 \% \mathrm{v} / \mathrm{v}$ $\mathrm{RBC}$ was used to examine the effect of hematocrit, and perfusing the IrS•AuNP100/RBC suspensions through a model vessel (cuboid microchannel) at a volumetric flow rate of $5 \mu 1 \mathrm{~min}^{-1}$ (equivalent to a wall shear rate of $50 \mathrm{~s}^{-1}$ ). In order to facilitate independent tracking of the RBC for comparative purposes, the hematocrit was spiked with $<1 \%$ CMFDA-labeled RBC, and the two luminescence channels were separated by excitation wavelength: IrS•AuNP100 were imaged with $\lambda_{\text {exc }}=355 \mathrm{~nm}, \lambda_{\text {em }}>510 \mathrm{~nm}$, and the labeled RBC were imaged with $\lambda_{\text {exc }}=475 \mathrm{~nm}, \lambda_{\mathrm{em}}>510 \mathrm{~nm}$.

The observation plane was located in the center of the channel with respect to the $x$-axis. Two image sets each containing 500 16-bit images taken with $4 \times 4$ binning $(128 \times 128$ pixels $)$ were acquired at 64 frames per second at each depth. The microscope was focused on the channel wall for the first image sequence (the channel wall was identified by focusing on occasional nanoparticles that had become stuck on the wall), and then the focal point was varied by increments of $5 \mu \mathrm{m}$ through the $z$-axis and image sequences captured at each depth in the channel. Image sets were converted to audio video interleave files for offline analysis of particle velocity.

\section{Calculation of particle velocity from audio video interleave}

Audio video interleaves were processed in the open source ImageJ64 software as 3D projections of the $x$-axis $/ y$ axis/time stacks, and were projected onto the $x$-axis. Background was subtracted from the images using a sliding paraboloid with 1.0 pixel rolling ball radius. Flowing luminescent nanoparticles or stained RBC appeared as diagonal tracks within the $y$-axis versus time projection. The angles of 20-30 track lines were measured manually at each depth and the velocities of the particles, with respect to the flow axis $\left(v_{y}\right)$, were calculated. To avoid bias, every line encountered on movement left to right across the $y$-axis versus time projection was measured. 
Tissue studies in mice

C57/B16 mice were obtained from Charles River (UK), and experiments conducted in accordance with the UK Animals (Scientific Procedures) Act under Home Office license PPL 30/2789. Mice were anesthetized using isoflurane (3\%, balance oxygen) and pilot data gathered initially using intracardiac or tail-vein injections of 100 $500 \mu \mathrm{l}$ sterile $80 \mathrm{pM}$ nanoparticle samples suspended in PBS, thereafter carotid artery infusions were performed to ensure homogeneous distribution of particles in organ perfusion. Animals were sacrificed at different times from 2-min to 1-h postinjection by cervical dislocation. Results reported for the 5- to 30-min postinjection as detailed below for ICPMS studies. Tissues including the mesentery, lung and extensor halluces proprius skeletal muscle were excised and immersed in 4\% paraformaldehyde in PBS for 15 min, washed with $3 \times$ PBS, and mounted onto glass coverslips with Vectashield (Vector Labs) mounting medium. Tissues were imaged within $5 \mathrm{~h}$ of euthanasia using an inverted microscope (Olympus IX-71) fitted with an LUCPLFLN $40 \times$ objective lens, numerical aperture 0.6, field number 22 and a variable focus collar with a working distance $2.7-4 \mathrm{~mm}$. In addition, the following organ samples were excised for digestion: lung, heart, spleen, gut, kidney, liver, brain, hindlimb muscle (gastrocnemius). Results are reported from M2 to M3 which were 5 min and M5 was 30-min postinjection. Tissue was frozen immediately postexcision, and then later defrosted for analysis. Glass vials were cleaned thoroughly with ultrapure aqua regia ( $\mathrm{HCl}: \mathrm{HNO}_{3}, 3: 1$, using ultrapure grade acids) before use. The organs were weighed, and then digested in sealed vials in aqua regia $(3 \mathrm{ml})$ and heated to $100^{\circ} \mathrm{C}$ for $10 \mathrm{~h}$. Samples were cooled and filtered (to remove and insoluble material) into Falcon tubes, and diluted to $10 \mathrm{ml}$. The samples were then analyzed for gold concentration by inductively coupled plasma mass spectrometry, performed on a 7500cx Agilent instrument. Gold concentrations were determined using PlasmaCal Calibration standard (QMX laboratories) of gold with $\mathrm{R}^{2}>0.999$ with linear calibration curve in all cases.

\section{Results \& discussion}

Preparation \& characterization of IrS•AuNP

The iridium complex, $\operatorname{IrSH}$ was synthesized from the bis-cyclometallated $\mu$-dichloro bridged complex, $\left[\operatorname{Ir}(\mathrm{ppy})_{2}(\mu-\right.$ $\mathrm{Cl})]_{2}$ [32], and bipyridine ligand, bpyhex, following introduction of the thioacetal group [19]. Prior to addition to the nanoparticles, the iridium complex IrSAc was fully characterized and its photophysical properties studied in both aerated $\mathrm{CH}_{3} \mathrm{CN}$ and aerated water with $1 \% \mathrm{CH}_{3} \mathrm{CN}$, to emulate the solvent conditions within an aqueous colloidal dispersion, while facilitating solubility. The IrSAc complex absorbs light in the UV-Vis with dominating bands at 230 and $255 \mathrm{~nm}$ attributed to ${ }^{1} \mathrm{LC}$ transitions and a weaker broad profile which extends from 300 to $450 \mathrm{~nm}$ characteristic of ${ }^{1}$ MLCT (metal to ligand charge transfer) transitions observed for the phenypyridine cyclometallated complexes [35,36]. Excitation of IrSAc in both aerated $\mathrm{CH}_{3} \mathrm{CN}$ and aerated water with $1 \% \mathrm{CH}_{3} \mathrm{CN}$ solutions at $405 \mathrm{~nm}$ produced a signal with a peak maximum of $585 \mathrm{~nm}$ in acetonitrile and $570 \mathrm{~nm}$ in $1 \% \mathrm{CH}_{3} \mathrm{CN}$ in $\mathrm{H}_{2} \mathrm{O}$ (Figure 2). At low temperature, $77 \mathrm{~K}$, the luminescence shifts of approximately $50 \mathrm{~nm}$ in the blue, which is indicative of a charge-transfer excited state (Supplementary Information). The luminescence quantum yield of aerated solution of IrSAc is increased in water to a value of $5 \%$ compared with $3 \%$ in $\mathrm{CH}_{3} \mathrm{CN}$ accompanied by an increase of the lifetime (Figure 2). Addition of the Zonyl7950 ${ }^{\circledR}$ surfactant, which is used subsequently in the formation of gold nanoparticles, led to a further increase in the luminescence lifetime and an increase of the quantum yield of the complex to $12 \%$.

Water soluble gold nanoparticles, Au13NP and Au100NP, were prepared from seeds initially synthesized by the citrate-reduction method [33], followed by a modified step-wise growth procedure, to give AuNP100 with an SPR peak maximum at $566 \mathrm{~nm}$ in an agreement with previous studies [37]. The nanoparticles were then treated with the fluorosurfactant, Zonyl7950 ${ }^{\circledR}$, in order to attach the iridium complex to the nanoparticles, without inducing flocculation and subsequent aggregation of the particles by directly replacing the negatively charged citrate shell with a cationic complex [19]. The IrSAc complex was treated with ammonium hydroxide to produce IrSH before addition to nanoparticles. A change of the $\zeta$ potential from $-33 \pm 5 \mathrm{mV}$ of the nonfunctionalized Au100NP to $-47 \pm 3 \mathrm{mV}$ was observed upon coating with the surfactant, followed by a further shift to $-33 \pm 3 \mathrm{mV}$ upon addition of a solution of freshly prepared IrSH. The shift of the Au13NP followed a similar trend from $-40 \pm 5$ to $-61 \pm 4$ and subsequently to $-35 \pm 5 \mathrm{mV}$. The change of the $\zeta$ potential to more positive numbers from the Zonyl-coated particles is indicative of the change of nanoparticle surface environment coated with the positively charged iridium metal center. The iridium-coated nanoparticles were isolated by centrifugation and dispersed in deionized water. TEM images of IrS•AuNP100 (Figure 3) showed mostly spherical particles with a diameter of $100 \pm 10 \mathrm{~nm}$, the particle clusters were apparent due to the drying process of the solution on the grid. The particle 


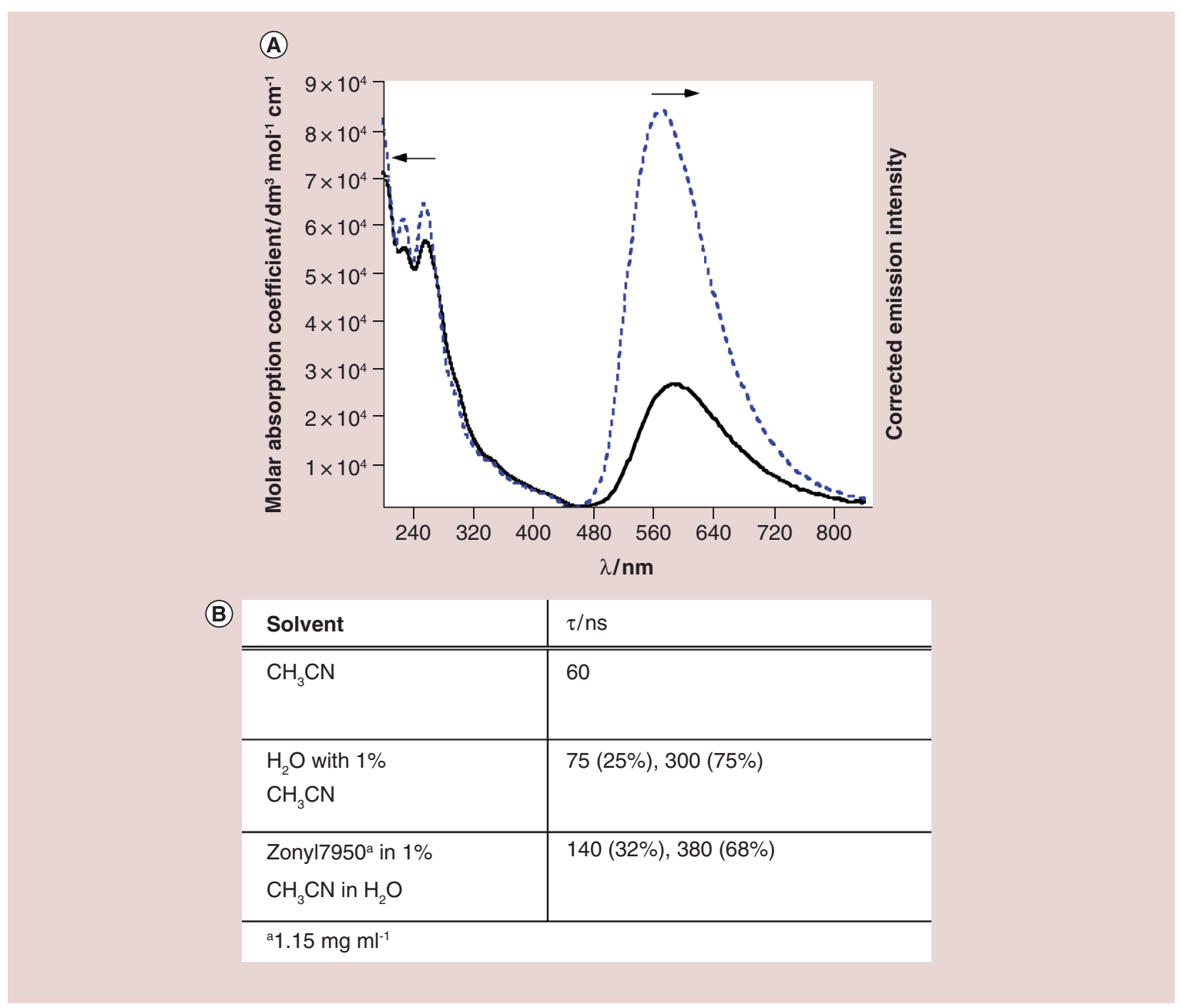

Figure 2. Photophysical studies of the IrSAc molecular probe in solution. (A) UV-Vis absorption and luminescence spectra ( $\lambda_{\text {exc }}=405 \mathrm{~nm}$ ) of $20 \mu \mathrm{m}$ IrSAc in $\mathrm{CH}_{3} \mathrm{CN}$ (solid line) and in $1 \% \mathrm{CH}_{3} \mathrm{CN}$ in $\mathrm{H}_{2} \mathrm{O}$ (blue hashed line); (B) Table of the luminescence lifetime data for IrSAc.

size was also measured in solution by nanoparticle tracking analysis, which revealed a mean particle diameter of $80 \mathrm{~nm}$ and a modal diameter of $100 \mathrm{~nm}$ (Figure 3) and by DLS, with a hydrodynamic radius of $70 \pm 20 \mathrm{~nm}$ in the number distribution (Supplementary Information). Aggregation did not occur upon addition of IrSH to the surfactant coated gold nanoparticles, as evidenced by the DLS, nanoparticle tracking analysis, TEM sizing of the IrS•AuNP100 particles and the retention of the SPR position of the particles in the UV-Vis spectrum (Figure 3). The SPR peak appears at $522 \mathrm{~nm}$ for IrS•AuNP13 and $568 \mathrm{~nm}$ for IrS•AuNP100, and even though the charge transfer band of the iridium is masked by the nanoparticle SPR in the UVvis, it shows clearly at the excitation spectrum. To evaluate if the brightness of the particles was sufficient for imaging, we mounted the nanoparticles IrS $\bullet$ AuNP100 on a coverslip and performed confocal fluorescence imaging studies $\left(\lambda_{\text {exc }}=405 \mathrm{~nm}\right)$. Clear, bright yellow spots of the nanoparticles were detected (Figure 3) characteristic of iridium luminescence. TEM images of the IrS•AuNP13 nanoparticles also reveal spherical particles and sizing information by DLS is also obtained (Supplementary Information).

ICP-OES gave an estimation of the metal ratio, iridium:gold, of the IrS•AuNP100 nanoparticles. Measurements of the digested IrS•AuNP100 nanoparticles gave an elemental composition of about $2000 \mathrm{Au}$ atoms per Ir atom, which is approximately 23,000 iridium complexes per IrS•AuNP100 nanoparticle, based upon the estimation that the $100 \mathrm{~nm}$ particles having 45.5 million gold atoms per nanoparticle, adapted from the previously reported calculation [19]. This corresponds to a footprint area of approximately $12 \AA \times 12 \AA$, in agreement with the metal 


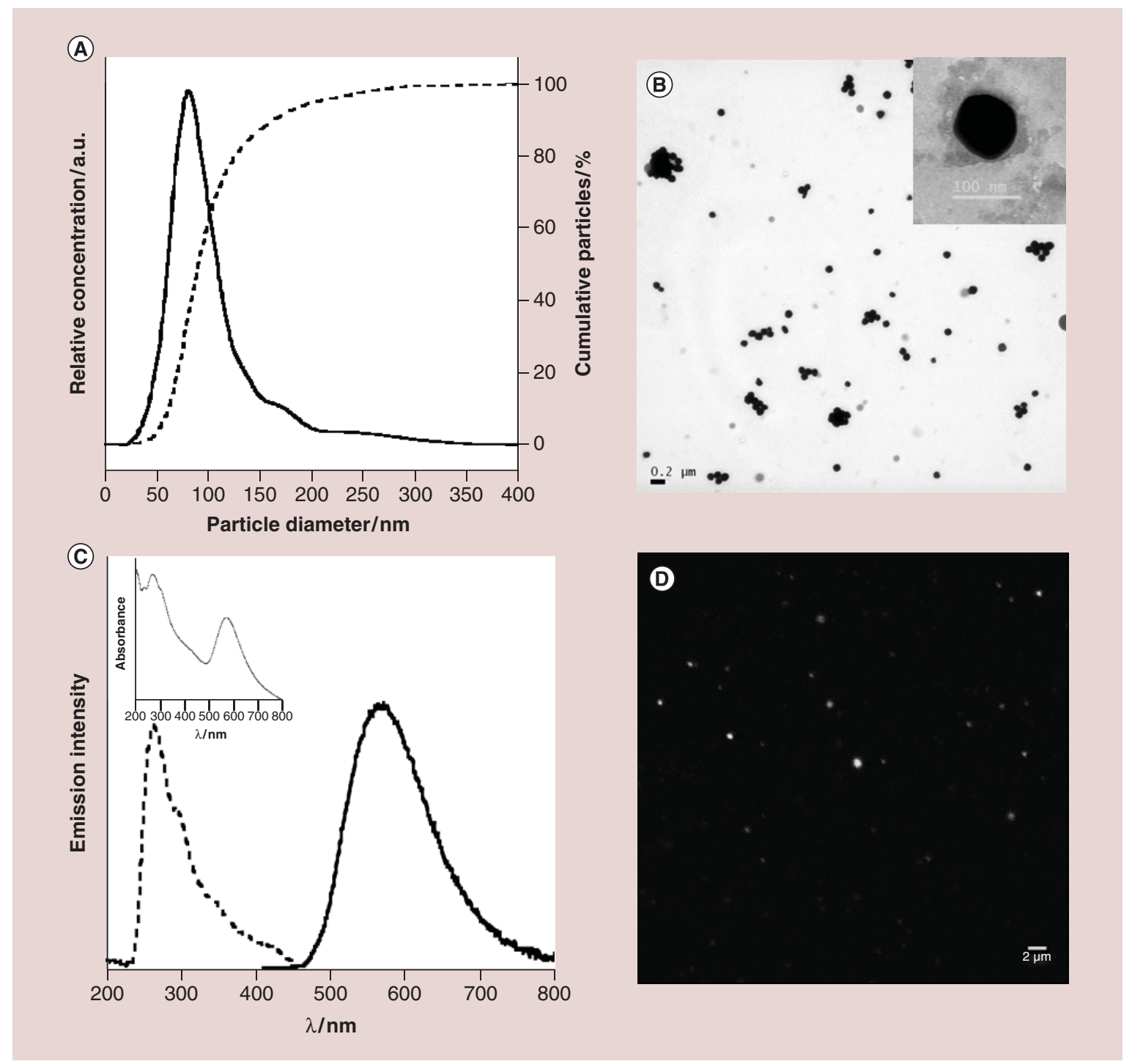

Figure 3. Characterization data and photophysical properties of iridium-coated nanoparticles. (A) Nanoparticle tracking analysis of IrS•AuNP100, showing relative number distribution of size (?), with a mean size of $80 \mathrm{~nm}$, and a modal diameter of $100 \mathrm{~nm}$. The cumulative number distribution is displayed (- - -). (B) Transmission electron micrograph of IrS•AuNP100, with zoomed-in image (inset) (C) Excitation, $\lambda_{e m}=550 \mathrm{~nm}$ (- - -) and emission spectra $\lambda_{\text {exc }}=405 \mathrm{~nm}$ (?) of $10 \mathrm{pM}$ IrS•AuNP100, inset UV-Vis absorption spectrum of IrS•AuNP100 $10 \mathrm{pM}$. (D) Confocal fluorescence image of IrS•AuNP100 mounted onto a coverslip with hydromount, $\lambda_{\mathrm{exc}}=405 \mathrm{~nm}, \lambda_{\mathrm{em}}=500-800 \mathrm{~nm}$.

complex size. For IrS•AuNP13 an atomic ratio of 106 Au atoms per Ir atom was found which corresponds to 940 iridium complexes per gold nanoparticle.

The isolated nanoparticles are emissive upon excitation at $405 \mathrm{~nm}$, with a peak $\lambda_{\max }$ at $570 \mathrm{~nm}$, as observed for the molecular complex in aqueous solution. A signature illustrating that the emission of the nanoparticles is originated from the iridium metal center is given by the excitation spectrum (Figure 3C) as it displays the features of the iridium-absorption spectrum. The quantum yields of luminescence of the IrS•AuNP13 and IrS•AuNP100 nanoparticles were found to be 14 and 19\% respectively, compared with only $5 \%$ for the complex in a predominantly aqueous environment. The increase of the quantum yield is attributed to the interaction of the molecular complex with the Zonyl7950 ${ }^{\circledR}$ fluorosurfactant. Independent examination of the quantum yield of the molecular complex $\mathrm{IrSH}$ in the solution with excess of Zonyl7950 ${ }^{\circledR}$. showed an of the IrSH quantum yield to $12 \%$ which is a similar increase observed for the coated 13 and $100 \mathrm{~nm}$ gold particles within the expected error of the quantum yield 
Figure 4. Luminescence imaging of iridium nanoparticles and RBC in flow. Overlay of time frames of selected consecutive luminescence images at 30 frames per second of: (A) IrS•AuNP100 (left, $\lambda_{\text {exc }}=355 \mathrm{~nm}$, $\lambda_{\mathrm{em}} \mathrm{nm}>510 \mathrm{~nm}$ ) and (B) green-stained RBC $\left(\lambda_{\text {exc }}=475 \mathrm{~nm}, \lambda_{\text {em }} \mathrm{nm}>510 \mathrm{~nm}\right)$ flowing in $10 \%$ hematocrit at $12 \mu \mathrm{m}$ channel depth, $5 \mu \mathrm{I} \mathrm{min}^{-1}$ flow rate.

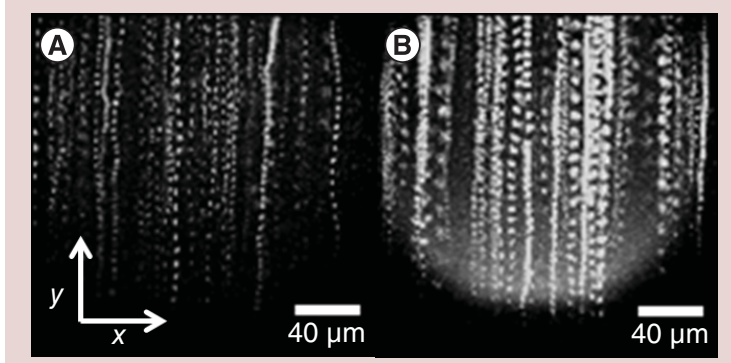

measurement. The effect of the coating of the fluorinated surfactant on metal complexes at different distances from the gold nanoparticle has been shown in a different study [38].

The luminescence lifetime of the IrS•AuNP100 aerated solution showed a biexponential decay fitted for 90 ns (10\%) and $400 \mathrm{~ns}(90 \%)$, significantly higher than the IrSAc complex in water and similar with that in the presence of the surfactant. These results are in agreement with the quantum yield studies showing that the fluorosurfactant not only facilitates stable colloid formation but also enhances the brightness of the particles. The luminescence signal of the nanoparticles IrS•AuNP100 seems far less oxygen-sensitive that the IrSAc with a deaerated lifetime of $85 \mathrm{~ns}(10 \%)$ and $420 \mathrm{~ns}(90 \%)$. This may be due to the inaccessibility of oxygen to the iridium luminescent center due to the protection by the surfactant and is highly desirable for biological imaging applications for two reasons: first, blood and biological tissue has significant triplet oxygen present, and quenching would reduce the brightness of luminescent probes in situ; second, the quenching process of triplet $\mathrm{O}_{2}$ with a triplet excited state usually produces singlet oxygen, which is highly reactive and has associated toxicity [39]. Finally, an MTT assay showed that there was no statistically significant change $(p>0.05)$ in cell viability following treatment of cells with any of the nanoparticles tested as assessed by one-way ANOVA and a post-hoc Tukey t-test (Supplementary Information). These results are in agreement with previous studies of the Zonyl-coated nanoparticles [19].

Imaging of luminescent IrS Au100NP in flows with red blood cells

To study the flow dynamic behavior of the IrS•AuNP100 particles and their potential as tracers to measure flow dynamics in the microvasculature, we initially studied them in vitro in cuboid microchannels as model vessels. Imaging studies of flows of the IrS•AuNP100 particles were evaluated against conventionally stained suspensions (RBC) with CellTracker GreenTM CFMDA which has close emission to the iridium probe (Figure 4).

There were noticeable, visual differences between the appearances of the IrS•AuNP100 and the dye-labeled $\mathrm{RBC}$ tracks (Figure 4) demonstrating the strong potential of the $100 \mathrm{~nm}$ gold nanoparticles for imaging flows against stained $\mathrm{RBC}$ which are approximately 70 -times larger. The nanoparticle tracking appeared as smaller, more well-defined spots of luminescence signal with more variance in the $x$-direction. It has been shown that when blood flows through vessels the flow fields enhance substance diffusion to a greater degree than simple Brownian motion [40] and in vitro models of micron tracer particles within RBC suspensions have also shown significant radial dispersions within the flow [41].

To determine the effects of depth of microchannel and hematocrit level, we studied suspensions of IrS•AuNP100 with stained-RBC (2 pM nanoparticles in PBS buffer) with varied hematocrit, 0-30\% v/v RBC. Video sequences of IrS•AuNP100 and stained-RBC were recorded at 64-frames per second, at varying depths into the channel, and were tracked manually to gain velocity $v_{y}$ data (Figure 5). The IrS•AuNP100 and labeled RBC were tracked sequentially at each depth from their emission $\left(\lambda_{\mathrm{em}}>510 \mathrm{~nm}\right)$ by switching the excitation wavelength between $\lambda_{\text {exc }}=355 \mathrm{~nm}$ for IrS•AuNP100 and $\lambda_{\text {exc }}=475 \mathrm{~nm}$ for the Green stained-RBC. For IrS•AuNP100 suspended only in PBS buffer and in $0 \%$ hematocrit, the particles could be tracked throughout the whole channel, and the expected parabolic flow profile was observed. A flow maximum of approximately $1100 \mu \mathrm{m} \mathrm{s}^{-1}$ was comparable to the simple model maximum flow value of $1250 \mu \mathrm{m} \mathrm{s}^{-1}$, assuming a Poiseuille flow between infinitely wide parallel plates (Figure 5A). This not only substantiated the suitability of the nanoparticles for determining flow rates but also facilitated calibration of the starting depth for the image sequences by fitting the data with a second-order polynomial and setting the turning-point as the center of the channel (i.e., channel depth of $50 \mu \mathrm{m}$ ). 
(A)

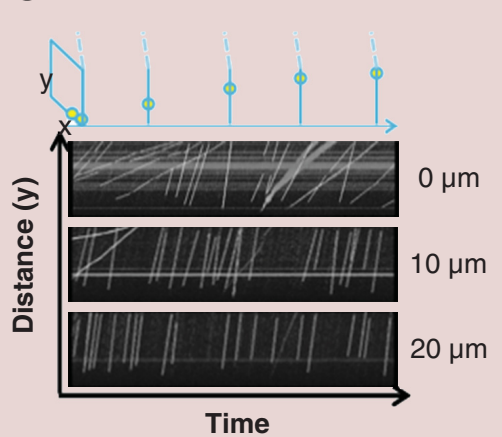

(C)

C) $\square$ IrS•AuNP100

Shaded bar: Green stained RBC

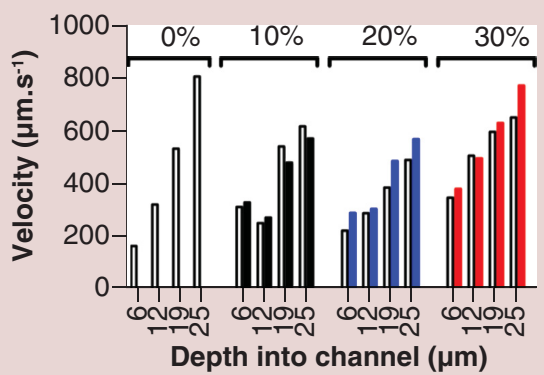

(B)

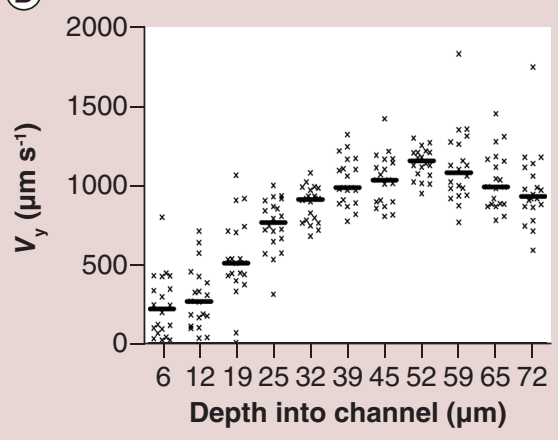

(D)

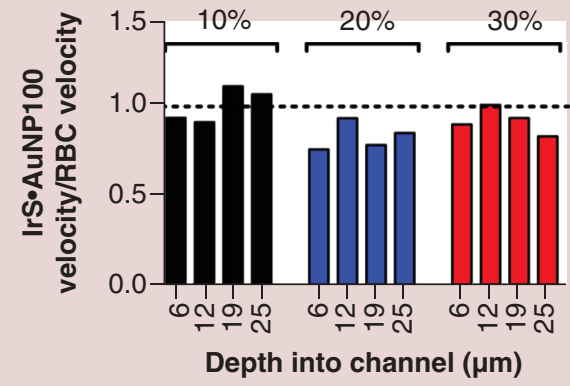

Figure 5. Velocity measurements of iridium nanoparticles in flow. (A) Schematic presentation with selected images to illustrate the experiment. (B) Plot of measured $v_{y}$ of IrS•AuNP100 suspended in PBS buffer, $0 \%$ hematocrit, at different depths up to $72 \mu \mathrm{m}$ from the wall of a cuboidal channel (depth $100 \mu \mathrm{m}$ ) when perfused at rate $5 \mu \mathrm{l} \mathrm{min}{ }^{-1},()$ data point, $(-)$ median vy. IrS•AuNP100 were visualized by their luminescence $\left(\lambda_{\mathrm{em}}>510 \mathrm{~nm}\right)$; (C) Median $\mathrm{v}_{\mathrm{y}}$ of IrS•AuNP100 (white bars) and green-stained RBC (shaded bars) in varied hematocrit (from 0 to $30 \%$ ) at depths up to $25 \mu \mathrm{m}$ from the channel wall when perfused at $5 \mu \mathrm{min}^{-1}$ through a cuboidal channel (depth $\left.100 \mu \mathrm{m}\right)$. (D) Relative velocity $v_{y}$ of IrS•AuNP100 to $v_{y}$ of RBC in varied hematocrit levels.

PBS: Phosphate-buffered saline; RBC: Red blood cell.

In our studies, luminescence microscopy imaging of the particles and the stained-RBC was possible up to a depth of approximately $25 \mu \mathrm{m}$ into the $10-30 \%$ hematocrit suspensions; beyond this, visualization was impaired by the opacity of the blood suspension at the visible wavelengths used. It is blood flow within the narrow channels of the vascular tree (from several tens of microns to as small as $8 \mu \mathrm{m}$ diameter) that is the least understood. These observations indicate that the IrS•AuNP100 would be suitable for imaging of such small channels. Videos of the nanoparticles in flow at different hematocrit levels in microchannels can be found in Supplementary Information.

Due to the significant size difference between IrS•AuNP100 and RBC, we hypothesized that hematocrit might affect the ability of nanoparticle tracers to follow the flow paths faithfully in the suspension. Indeed, blood rheology can significantly affect the flow characteristics of smaller hematopoietic cells in vivo, such as margination of platelets to the walls of blood vessels $[42,43]$. However, we observed that the hematocrit did not affect the velocity $v_{\mathrm{y}}$ of the particles at any of the depths studied, and normalization of the velocity of IrS•AuNP100 to the velocity of RBC (Figure 5C) showed that the particles followed the flow speeds of the RBC in all cases. The presence of fibrinogen and other macromolecules within blood often supports the assembly of RBC into tube-like aggregates, known as 'rouleaux', at low shear rates, and plug-flow dynamics can arise, which tend to blunt the flow profile and alter the degree of margination of certain species within particulate flow [44]. RBC aggregation can be artificially manipulated in vitro using dextrans of different molecular weights [43]. In the studies above, RBC were suspended in PBS and thus not undergoing aggregation. Therefore, in order to investigate whether aggregation conditions may alter the velocity of the nanoparticles in flow, 30\% hematocrit was prepared in 1\% Dextran500 (aggregating) and 2\% Dextran40 (nonaggregating viscosity control), and IrS•AuNP100 and RBC were tracked up to a depth 
of $25 \mu \mathrm{m}$ (Supplementary Information). RBC aggregation was verified by bright-field microscopy using a static sample, but under flow conditions aggregation did not appear to alter the velocity, $v_{y}$ of either the IrS•AuNP100 or the RBC indicating that aggregation of plug flow does not affect the tracking efficiency of the nanoparticles. In addition, the number of tracks seen near the wall (at a depth of $6 \mu \mathrm{m}$ ) over 500 frames was equivalent in both dextrans, indicating that plug-flow induced margination was not observed. These results are noteworthy in terms of the ability of nanoparticles to act as faithful flow tracers regardless of their position within the channel, perhaps regardless of the architecture of the vasculature being examined. This may be significant for the study of blood vasculature in vivo in the early diagnosis of such conditions as heart disease, ischemia, embolism, aneurysm and stroke where abnormal changes inflow are indicative of the pathological state and, hence, prophylactic treatment can be initiated. While these are mainly large vessel disorders, flow disturbance will be most marked near the wall, and thus potentially open to visualization using nanoparticles. In addition, cell-vessel wall interactions during thrombosis or inflammation, and in the formation of atherosclerotic plaques, could potentially be studied. Our nanoparticles, therefore, present a unique opportunity to explore the microvasculature or disturbance of flow near the wall of larger vessels, in terms of resolution and size, and when combined with their ability to track blood flow faithfully under a range of blood rheologies, they represent a highly suitable tool for imaging. Furthermore, it is important to be able to study the fate of nanoparticles introduced into the circulatory system. An important criterion for tracers to study whole-body nanoparticle distributions is their detection by inexpensive methods; as we have demonstrated here, our nanoparticles can be easily visualized both in blood and in tissues (vida infra) due to their brightly luminescent iridium(III) complex coating.

Fate of luminescent IrS•Au100NP injected into mice

A solution of IrS•AuNP100 nanoparticles in PBS was injected into mice and excised tissue sections of the lungs, mesentery and extensor hallucis proprius skeletal muscle were imaged upon wet mounting onto coverslips. IrS•AuNP100 were observed by epiluminescence microscopy in all tissues (Figures $6 \& 7$ ).

An approximately $100 \mu \mathrm{m}$ diameter blood vessel was located within the mesentery tissue. Under bright-field microscopy, RBC filling the vessel and endothelial cells lining the vessel, were visible (Figure 6A) and spots of luminescence detected at the emission range of the IrS•AuNP100 were clearly visible in the image (Figure 6B). Characteristic skeletal muscle fibers were visible in the extensor hallucis proprius striated muscle under bright-field microscopy (Figure 6C) and point-sources of luminescence indicative of the nanoparticles were observed under epiluminescence detection. A signature of the origin of the luminescence is given by collection of the steady-state luminescence spectra from the fields of view. They displayed the characteristic peak expected for IrS•AuNP100 (Figure 6D inset), which together with luminescence lifetimes (measured from image with a $375 \mathrm{~nm}$ laser at $550 \mathrm{~nm}$ to be $86 \mathrm{~ns}(15 \%)$ and $320 \mathrm{~ns}(85 \%)$, confirmed that the nanoparticles had reached the small vessels within this tissue. The nanoparticles were similarly detected in the tissue from the lung (Figure 7) showing clear detection of the iridium signal.

To gain an understanding of the biodistribution of the nanoparticles we examined the gold content in organs using inductively coupled plasma mass spectrometry. We report the analysis of the gold content of excised organs in four different specimens (Figure 8).

Our studies showed zero background with negative controls (M6, saline injection), a dose-dependent effect with injected particle number (a consistent M3 > M2 signal) and a longer circulation effect (M5) which also confirms clearance from gut, kidney and brain. It is of interest that clearance of nanoparticles (unlike microparticles) may be greater in the viscera (e.g., liver and spleen with sinusoidal, fenestrated endothelium) rather than the lung (with continuous endothelium).

This accumulation is likely to reflect the normal clearance mechanisms for foreign bodies and hence accumulation in lung and liver is to be expected. The NP biodistribution is more likely to be unperturbed by haemodynamics (unlike e.g., microspheres where they may be streaming with arterial flow). Finally, the short circulate time is an order of magnitude shorter than the latest time point, confirming that the results are as expected for these acute studies.

\section{Conclusion}

We have shown that our approach using a fluorinated surfactant to coat gold nanoparticles led to luminescent iridium nanoparticles as bright probes with an optical window of luminescence detectable in blood and are introduced as attractive flow tracers in blood, giving measured particle velocities that are independent of the hematocrit, showing 

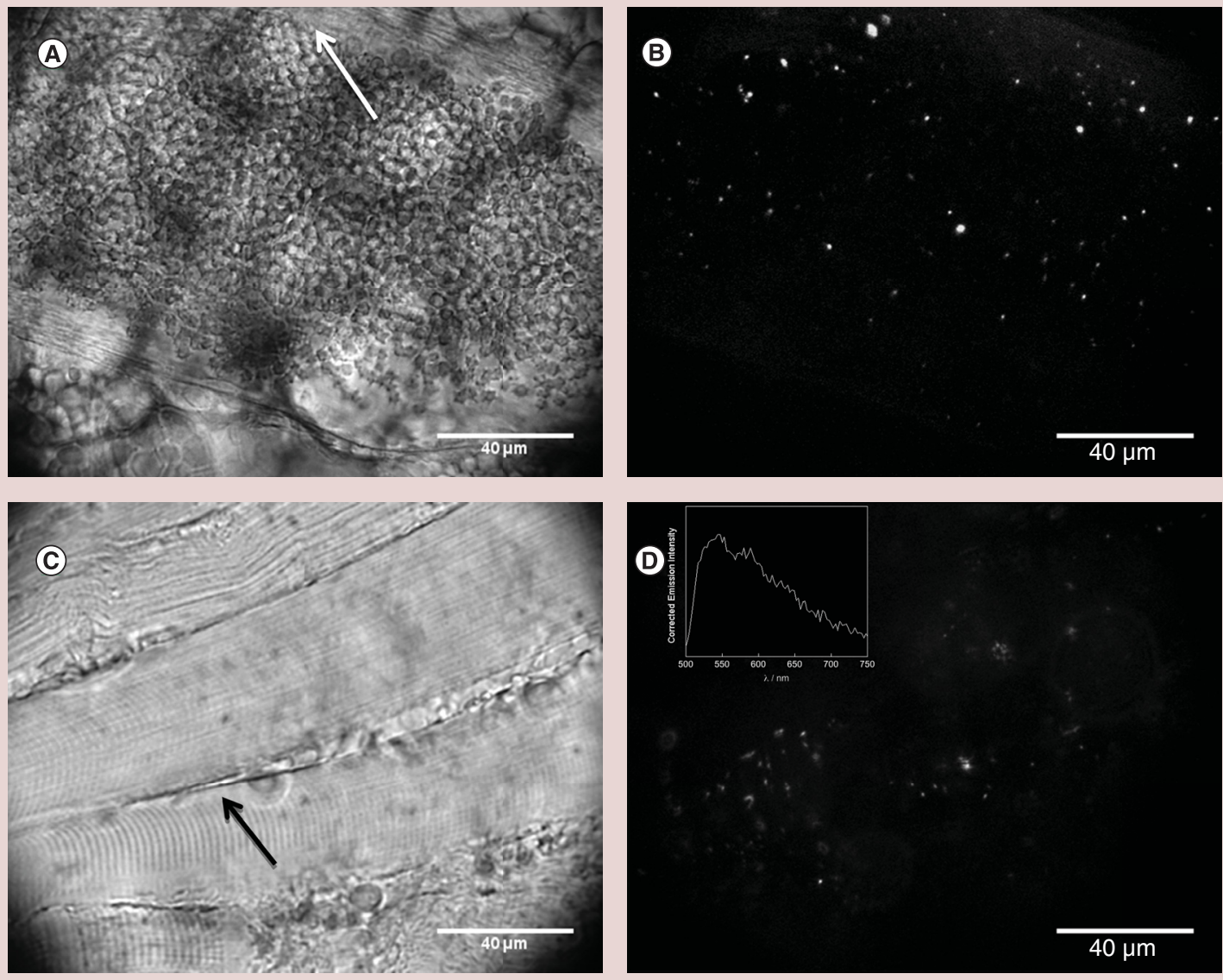

Figure 6. Optical imaging of iridium nanoparticles in excised tissues. Bright field (A \& $C$ ) and luminescence images ([B \& D] $\lambda_{\text {exc }}=405 \mathrm{~nm}, \lambda_{\mathrm{em}}>510$ ) of a small blood vessel in the mesentery (A \& B), with the white arrow indicating the endothelial cells lining the vessel (adipocytes are evident as spherical objects beneath the vasculature), and in the skeletal muscle (C \& D) of a mouse injected with IrS•AuNP100, with the black arrow indicating the striated muscle fibers; blood vessels appear between fibers. The steady-state emission spectrum obtained from the field of view in image $d$ is shown (inset).

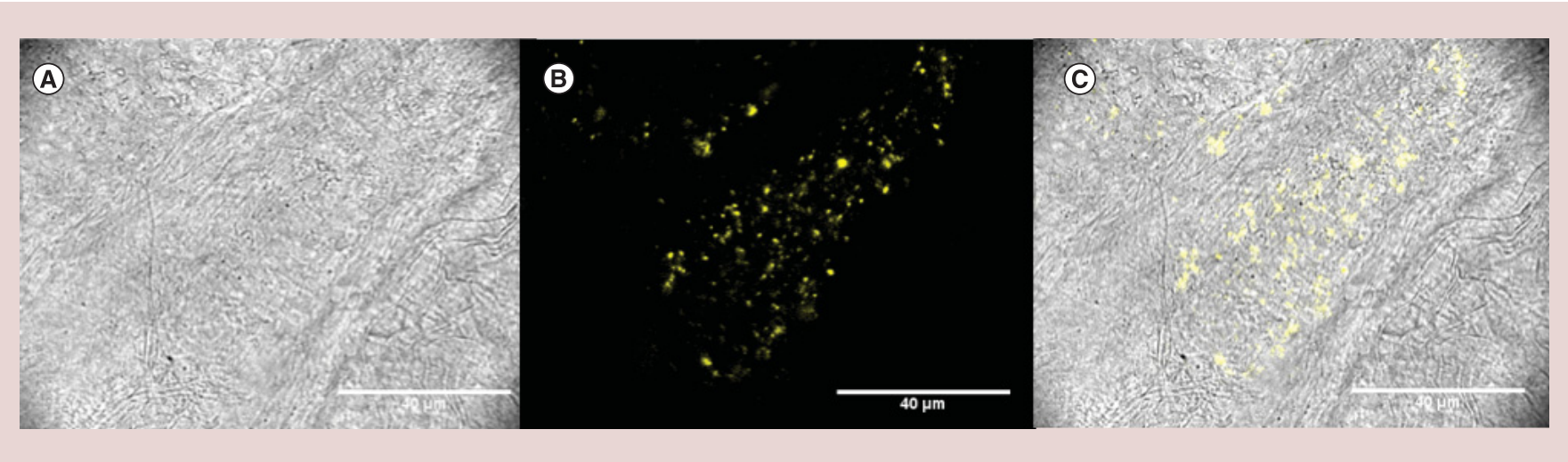

Figure 7. Transmission (A), epiluminescence (B) and overlay (C) of transmission and epiluminescence images $\left(\lambda_{\text {exc }}=405 \mathrm{~nm}, \lambda_{\mathrm{em}}>510\right)$ of blood capillaries in lung tissue of a mouse (sample M3) injected with IrS•AuNP100. 
Figure 8. Gold content in four specimen mice, administered by carotid artery cannulation IrS•AuNP100 (80 pM, M2- $100 \mu \mathrm{l}, \mathrm{M3}-200 \mu \mathrm{l}$ 5-min postinjection), or (80 pM, M5-500 $\mu$ l 30-min postinjection). M6 is a control, with a saline carotid artery cannulation injection.

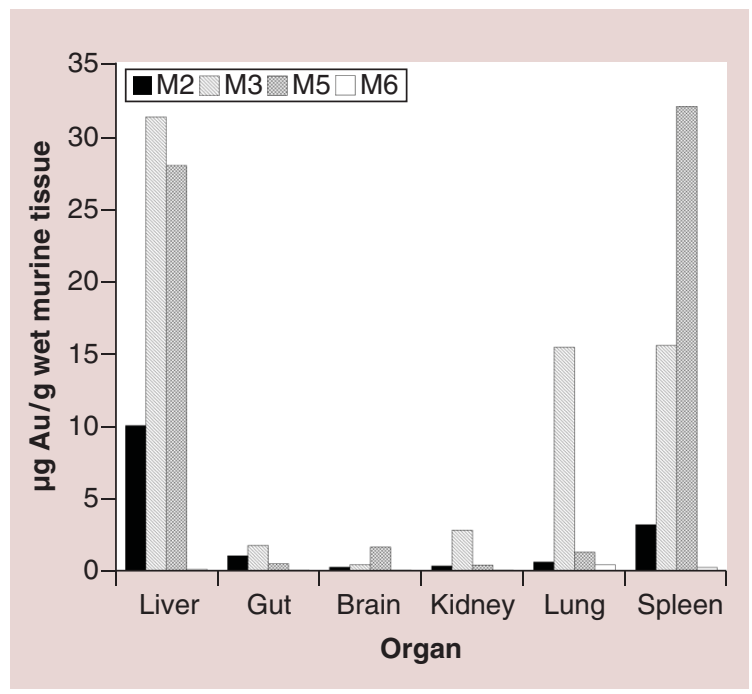

no interaction with other parts of the media. Most importantly the size of the $100 \mathrm{~nm}$ nanoparticles, IrS•AuNP100, is ideal for imaging for the nanoparticles as not only they track blood flow reliably but they can be detected using conventional fluorescence microscopes with good resolution. The nanoparticles report on flow close to the vessel walls, where disease such thrombosis, inflammation and plaque formation require detailed flow velocity analysis but also can be studied in depths up to $25 \mu \mathrm{m}$ in physiologically relevant hematocrit levels. The particles entered blood circulation when injected in mice and they were detected within surgically-excised organs by luminescence imaging. The $100 \mathrm{~nm}$ nanoparticles were clearly detected in the vasculature in small vessels with the characteristic iridium signal, which is away from any auto-fluorescence or scattering, representing their potential for in vivo imaging and tracking. Interestingly, they show good clearance from blood by liver and spleen 5-min postinjection in low nanoparticle loading, although further studies may provide more detail about clearance pathways. Our approach provides a paradigm of nanoparticle development which has potential to in vivo imaging using near-infra red emitting probes. Studies of blood flow dynamics using nanoparticles will not only improve our understanding of the circulatory system function but can also enable new levels of analysis in blood flow studies in in vivo disease models.

Financial \& competing interests disclosure

We wish to thank EPSRC for support (EP/F50053X/1 and Developing Impact internal grant), Leverhulme Trust and the University of Birmingham for financial support. Some of the spectrometers used in this research were obtained through Birmingham Science City: Innovative Uses for Advanced Materials in the Modern World (West Midlands Centre for Advanced Materials Project 2), with support from Advantage West Midlands (AWM) and partial funding from the European Regional Development Fund (ERDF). The authors have no other relevant affiliations or financial involvement with any organization or entity with a financial interest in or financial conflict with the subject matter or materials discussed in the manuscript apart from those disclosed.

No writing assistance was utilized in the production of this manuscript.

Ethical conduct of research

The authors state that they have obtained appropriate institutional review board approval or have followed the principles outlined in the Declaration of Helsinki for all human or animal experimental investigations. In addition, for investigations involving human subjects, informed consent has been obtained from the participants involved.

Supplementary data

To view the supplementary data that accompany this paper please visit the journal website at: www.futuremedicine.com/doi/full/10.2217/nnm-2017-0211

Open access

This work is licensed under the Attribution-NonCommercial-NoDerivatives 4.0 Unported License. To view a copy of this license, visit http://creativecommons.org/licenses/by-nc-nd/4.0/ 
Summary points

- Gold nanoparticles, 13 and $100 \mathrm{~nm}$, are coated with a luminescent surface active iridium metal complex to yield IrS•AuNP13 and IrS•AuNP100, respectively.

- The nanoparticles display yellow-green luminescence, with a peak centered at $570 \mathrm{~nm}$ and exhibit enhanced quantum yields compared with the molecular complex and lifetimes up to $420 \mathrm{~ns}$.

- It is estimated by inductively coupled plasma optical emission spectroscopy that about 23,000 iridium complexes are attached per IrS•AuNP100 nanoparticle.

- Analysis of nanoparticle velocities in narrow channels shows that they are independent of hematocrit level.

- The IrS•AuNP100 nanoparticles report on flow at the vessel walls, and can be studied down to depth of $25 \mu \mathrm{m}$ in the channel.

- Injection of the nanoparticles into mice shows that the nanoparticles enter blood circulation.

- Luminescence imaging reveals nanoparticles in vessels in lungs, mesentery and the skeletal muscle. Spectral collection of the images shows the characteristic iridium luminescence profile and lifetime.

- The nanoparticles show good clearance from organs based on inductively coupled plasma-massspectrometry analysis of tissues.

\section{References}

Papers of special note have been highlighted as: $\bullet$ of interest; $\bullet \bullet$ of considerable interest.

1 Diao S, Blackburn JL, Hong G et al. Fluorescence imaging in vivo at wavelengths beyond 1500 nm. Angew. Chem. Int. Ed. Engl. 127(49), 14758-14762 (2015).

- Recent advances in fluorescence imaging technology allow in vivo detection in near infrared.

2 Fei P, Lee J, Packard RRS et al. Cardiac light-sheet fluorescent microscopy for multi-scale and rapid imaging of architecture and function. Sci. Rep. 6, 22489 (2016).

-• Potential of fluorescence imaging of reconstructing cardiac muscle.

3 Ha H, Nam KH, Lee SJ. Hybrid PIV-PTV technique for measuring blood flow in rat mesenteric vessels. Microvasc. Res. 84(3), 242-248 (2012).

- Importance of particle imaging velocimetry and particle tracking velocimetry technique for measuring blood flow.

4 Luu NT, Rainger GE, Buckley CD, Newsome PN, Frampton J, Nash GB. Mesenchymal stem cells inhibit recruitment of flowing neutrophils and lymphocytes by endothelial cells: roles of Interleukin-6 and transforming growth factor-beta. Heart 97(20), 19-20 (2011).

5 Ravnic DJ, Zhang YZ, Tsuda A, Pratt JP, Huss HT, Mentzer SJ. Multi-image particle tracking velocimetry of the microcirculation using fluorescent nanoparticles. Microvasc. Res. 72(1-2), 27-33 (2006).

6 Douma K, Prinzen L, Slaaf DW et al. Nanoparticles for optical molecular imaging of atherosclerosis. Small 5(5), 544-557 (2009).

7 Chauhan VP, Stylianopoulos T, Martin JD et al. Normalization of tumour blood vessels improves the delivery of nanomedicines in a size-dependent manner. Nat. Nanotech. 7(6), 383-388 (2012).

8 Popović Z, Liu W, Chauhan VP et al. A nanoparticle size series for in vivo fluorescence imaging. Angew. Chem. Int. Ed. Engl. 49(46), 8649-8652 (2010).

- Importance of nanoparticle size in improving the resolution for in vivo imaging.

9 Xiang J, Cai X, Lou X et al. Biocompatible green and red fluorescent organic dots with remarkably large two-photon action cross sections for targeted cellular imaging and real-time intravital blood vascular visualization. ACS Appl. Mater. Interfaces 7, 14965-14974 (2015).

10 Bartczak D, Muskens OL, Sanchez-Elsner T, Kanaras AG, Millar TM. Manipulation of in vitro angiogenesis using peptide-coated gold nanoparticles. ACS Nano 7(6), 5628-5636 (2013).

11 Lemon CM, Karnas E, Han XX et al. Micelle-encapsulated quantum dot-porphyrin assemblies as in vivo two-photon oxygen sensors. J. Am. Chem. Soc. 137(31), 9832-9842 (2015).

12 Han H-S, Martin JD, Lee J et al. Spatial charge configuration regulates nanoparticle transport and binding behavior in vivo. Angew. Chem. Int. Ed. Engl. 52(5), 1414-1419 (2013).

13 Hong GS, Robinson JT, Zhang YJ et al. In vivo fluorescence imaging with Ag2S quantum dots in the second near-infrared region. Angew. Chem. Int. Ed. Engl. 51(39), 9818-9821 (2012).

14 Austin LA, Kang B, El-Sayed MA. Probing molecular cell event dynamics at the single-cell level with targeted plasmonic gold nanoparticles: a review. Nano Today 10(5), 542-558 (2015).

15 Gilijohann DA, Seferos DS, Daniel WL, Massich MD, Patel PC, Mirkin CA. Gold nanoparticles for biology and medicine. Angew. Chem. Int. Ed. Engl. 49, 3280-3294 (2010). 
16 Boisselier E, Astruc D. Gold nanoparticles in nanomedicine: preparations, imaging, diagnostics, therapies and toxicity. Chem. Soc. Rev. 38(6), 1759-1782 (2009).

17 Parak WJ. Nanomaterials-controlled interaction of nanoparticles with cells. Science 351(6275), 814-815 (2016).

18 Wei A, Thomas M, Mehtala J, Wang J. 13 - gold nanoparticles (GNPs) as multifunctional materials for cancer treatment A2 - Park, Kinam. In: Biomaterials for Cancer Therapeutics. Woodhead Publishing, e349-e389 (2013).

19 Rogers NJ, Claire S, Harris RM et al. High coating of Ru(II) complexes on gold nanoparticles for single particle luminescence imaging in cells. Chem. Commun. 50(5), 617-619 (2014).

- Introduction of $100 \mathrm{~nm}$ nanoparticles with ruthenium metals for imaging in cancer cells.

20 Lewis DJ, Dore V, Rogers NJ et al. Silica nanoparticles for micro-particle imaging velocimetry: fluorosurfactant improves nanoparticle stability and brightness of immobilized iridium(III) complexes. Langmuir 29(47), 14701-14708 (2013).

21 Ackerman CM, Lee S, Chang CJ. Analytical methods for imaging metals in biology: from transition metal metabolism to transition metal signaling. Anal. Chem. 89(1), 22-41 (2017).

22 Fernandez-Moreira V, Thorp-Greenwood FL, Coogan MP. Application of d6 transition metal complexes in fluorescence cell imaging. Chem. Commun. 46(2), 186-202 (2010).

23 Davies A, Lewis DJ, Watson SP, Thomas SG, Pikramenou Z. pH-controlled delivery ff luminescent europium coated nanoparticles into platelets. Proc. Nat. Acad. Sci. USA 109(6), 1852-1867 (2012).

24 Lewis DJ, Bruce C, Bohic $S$ et al. Intracellular synchrotron nanoimaging and DNA damage/genotoxicity screening of novel lanthanide-coated nanovectors. Nanomedicine 5, 1547-1557 (2010).

25 Lewis DJ, Day TM, Macpherson JV, Pikramenou Z. Luminescent nanobeads: attachment of surface reactive Eu(III) complexes to gold nanoparticles. Chem. Commun. (13), 1433-1435 (2006).

26 Miomandre F, Stancheva S, Audibert JF et al. Gold and silver nanoparticles functionalized by luminescent iridium complexes: synthesis and photophysical and electrofluorochromic properties. J. Phys. Chem. C 117(24), 12806-12814 (2013).

27 Nasr G, Guerlin A, Dumur F et al. Dithiolate-appended iridium(III) complex with dual functions of reducing and capping agent for the design of small-sized gold nanoparticles. J. Am. Chem. Soc. 133(17), 6501-6504 (2011).

28 Hallett AJ, Broomfield M, Christian P, Pope SJA. Silver nanoparticles functionalised with a luminescent iridium complex: phosphorescent hybrid materials. Trans. Met. Chem. 39(2), 195-198 (2014).

29 Lo KK-W. Luminescent rhenium(I) and iridium(III) polypyridine complexes as biological probes, imaging reagents, and photocytotoxic agents. Acc. Chem. Res. 48(12), 2985-2995 (2015).

30 Lamola Aa RM. Fluorescence excitation spectrum of bilirubin in blood: a model for the action spectrum for phototherapy of neonatal jaundice. Photochem. Photobiol. 90, 294-296 (2015).

31 Hong Y-R, Gorman CB. Synthetic approaches to an isostructural series of redox-active, metal tris(bipyridine) core dendrimers. J. Org. Chem. 68(23), 9019-9025 (2003).

32 Sprouse S, King KA, Spellane PJ, Watts RJ. Photophysical effects of metal-carbon.sigma. bonds in ortho-metalated complexes of iridium(III) and rhodium(III). J. Amer. Chem. Soc. 106(22), 6647-6653 (1984).

33 Grabar KC, Freeman RG, Hommer MB, Natan MJ. Preparation and characterization of Au colloid monolayers. Anal. Chem. 67, 735-743 (1995).

34 Butler LM, Jeffery HC, Wheat RL et al. Karposi's sarcoma-associated herpesvirus infection of endothelial cells imhibits neutrophil recruitment through as interleykin-6-dependent mechanism: a new paradigm for viral immune evasion. J. Virology 85(14), 7321-7332 (2011).

35 Costa RD, Ortí E, Bolink HJ et al. Archetype cationic iridium complexes and their use in solid-state light-emitting electrochemical cells. Adv. Funct. Mat. 19(21), 3456-3463 (2009).

36 Wu S-H, Ling J-W, Lai S-H, Huang M-J, Cheng CH, Chen IC. Dynamics of the excited states of $\left[\operatorname{Ir}(\text { ppy })_{2} \text { bpy }\right]^{+}$with triple phosphorescence. J. Phys. Chem. A 114(38), 10339-10344 (2010).

- Shows the effect of distance of metal center from nanoparticle surface and the influence of surfactant.

37 Ziegler C, EychmüLler A. Seeded growth synthesis of uniform gold nanoparticles with diameters of $15-300 \mathrm{~nm}$. J. Phys. Chem. C 115(11), 4502-4506 (2011).

38 Osborne SAM, Pikramenou Z. Highly luminescent gold nanoparticles: effect of ruthenium distance for nanoprobes with enhanced lifetimes. Farad. Discuss. 185(0), 219-231 (2015).

39 Ruggi A, Van Leeuwen FWB, Velders AH. Interaction of dioxygen with the electronic excited state of ir(III) and ru(II) complexes: principles And biomedical applications. Coord. Chem. Rev. 255(21-22), 2542-2554 (2011).

40 Ahuja AS, Hendee WR, Carson PL. Transport phenomena in lamina flow of blood. Phys. Med. Biol. 23, 928-936 (1978).

41 Saadatmand M, Ishikawa T, Matsuki $\mathrm{N}$ et al. Fluid particle diffusion through high hematocrit blood flow within a capillary tube. J. Biomechanics 44(1), 170-175 (2011). 
Research Article Rogers, Jeffery, Claire et al.

42 Yeh C, Eckstein EC. Transient lateral transport of platelet-sized particles in flowing blood suspensions. Biophys. J. 66(5), 1706-1716 (1994).

43 Nash GB, Watts T, Thornton C, Barigou M. Red cell aggregation as a factor influencing margination and adhesion of leukocytes and platelets. Clin. Hemor. Microcir. 39(1), 303-310 (2008).

44 Pries AR, Secomb TW, Gaehtgens P. Biophysical aspects of blood flow in the microvasculature. Cardiovasc. Res. 32(4), 654-667 (1996). 